\title{
Factors Associated with Hand Washing Practices among Secondary School Students in Ndorwa East Constituency in Kabale District
}

\author{
Twinomuhwezi Benja*, Byamukama Topher, Nshakira Nathan \\ Department of Community Health, Kabale University, Kabale, Uganda
}

\begin{abstract}
Despite the worldwide Global Hand Washing Day campaign, which targets school children as the most effective agents for behaviour change, there is limited documentation in various school settings. The purpose of the study was to assess the factors associated with hand washing practices among secondary school students in Ndorwa East Constituency in the Kabale district. The study used both quantitative and qualitative methods to collect data from a sample of 291 students from five schools. Results: Of the 291 respondents enrolled, 219(77\%) washed their hands after the rest room. Factors associated with a higher likelihood of hand washing practice among secondary school students in Ndorwa East Constituency-Kabale District were being aged <18 years (aOR =8.1, 95\%CI: 2.6521.61, $p<0.001$ ), presence of water for hand washing (aOR =50.7,95\%CI:11.50-309.38,p<0.001), presence of hand washing stations (aOR=7.3,95\%CI:2.72-30.37, $p<0.001)$, and cleanliness of hand washing stations (aOR=70.0,95\%CI:10.44-605.6, $p<0.001)$. The factors associated with hand washing practices were presence of water for hand washing, the presence of hand washing stations in schools, cleanliness of hand washing stations. The study suggests that the school administrators should sensitize all students to continue practicing washing hands. This would help in preventing students from diseases associated with poor hand hygiene practices.
\end{abstract}

Keywords: Hand washing, Knowledge, Secondary school.

\section{Introduction}

Hand washing is defined as the act of washing hands with plain or antimicrobial soap and water with the purpose of removing dirt, organic materials and other organisms that cause disease. Hand washing with soap is among the most effective and inexpensive ways to prevent infectious diseases. Every year, pneumonia and diarrhoea kill 14 million children under five [1]. This simple behaviour can save lives, cutting deaths associated with Diarrhoea by almost one-half and deaths from acute respiratory infections by nearly onequarter. Hand washing with soap not only helps people improve their health but also removes barriers to economic opportunity, allows children to learn and grow, and helps strengthen communities [2].
The CDC states that hand washing practices are meant to protect all from the risks of sicknesses. Hand washing should apply to the three basic rules of, before, during and after, doing certain things such as before, during and after cooking food, before and after eating, before and after treating a wound, before and after caring for a patient, after visiting the toilet and after holding a pet of a wild animal. According to the $\mathrm{CDC}$, hand washing practice is easy, and it's the most effective way to prevent the spreading of germs because germs can spread from one person to another and spread throughout the entire community [3].

Diarrhoea, mainly due to contaminated food and water and poor hand washing practices, affects 1.7 billion people annually across the world. It is the second-largest killer of children under five years old $[4,5]$. 
The Global Burden of Disease Study 2015 reported that the prevalence of diseases attributable to poor hand hygiene has steadily declined since the 1990s and that mortality and disability-adjusted life years (DALY) attributed to no hand washing have declined since 2000 . Progress in reducing environmental risks was mainly driven by sizeable reductions in mortality and disease burden attributable to unsafe water, sanitation, and hygiene (WASH). Between 2005 and 2015, the number of deaths attributable to unsafe water and no hand washing with soap globally fell by more than $12 \%$, whereas DALYs decreased by more than $20 \%$ [6].

A study done by [7] revealed that hand washing practices among secondary school students are still poor, most especially on the African continent, yet proper hand washing would be useful in preventing many diseases amongst the students and the entire population. School settings are important contexts for educating students about hygienic behaviours such as hand washing practices.

In a study done by [8] in India about assessment of knowledge, attitude, and practice of hand hygiene among secondary students, it was revealed that the overall knowledge of the participants was moderate (ranging between $63.1 \%$ to $64 \%$ ). When the results were analyzed based on the scoring system, only a few (6.4\%) scored poor.

A study done by [9] shows that out of 285 children who used school toilets during the study period, 257 (90.2\%) indicated that they washed their hands. Out of the 257 , a greater proportion, $88.3 \%$, did the hand washing with soap. Similarly, washing hands and washing hands with soap before eating showed similar trends. The data showed that school children in private schools were $63 \%$ less likely to wash their hands with soap after defecation than school children from public schools.

A study by [10] indicates that students who practice proper hand washing were less likely to report gastrointestinal and respiratory symptoms than students who do not practice proper hand washing. Hand washing with soap has also been reported to reduce death related to Diarrhoea by $44 \%$ and respiratory infections by $23 \%$ [11].

In Uganda, hand washing with soap by adults after using toilets increased from $36 \%$ to $37 \%$ in the 2016/2017 financial year. This reflects that only three out of every ten Ugandans wash their hands with soap after using the toilet [12].

Studies in Uganda have found a discrepancy between knowledge and practice of hand washing. For example, many students in secondary schools are aware of the reasons and importance of hand washing, yet the majority do not properly practice hand washing during critical times like before eating food and after visiting toilets/ latrines [13].

According to the [14], Ndorwa East Constituency was among the areas in Uganda with the highest cholera incidences, which could be prevented by proper hand washing. Strategies by the Government of Uganda and non-government Organizations such as the use of tippy taps have been promoted in communities in Kabale district, and yet some schools in Ndorwa East Constituency have been reported to have an unfavourable environment in schools that do not favour students to wash their hands properly.

\section{Research Gaps and Summary}

All external parts of the body need attention, time and care, and water plays a major role in ensuring this. To achieve the international development target of having the proportion of people without access to improved water and sanitation by 2015, 1.5 billion people will require access to water supply, and about 2.2 billion people will require access to sanitation facilities [13]. Other basic facilities needed in the schools include decent classrooms, water closet toilets, dustbins, water bowls, soaps, disinfectants, deodorants, tissue papers, good playgrounds, napkins, incinerators [15]. 
Although several studies have been carried out relating to hand washing among secondary school students, some aspects have not been exhausted, which have created research gaps that need to be filled. Such aspects include knowledge of students, enabling and inhibiting factors for hand washing among students and policy guidelines in place for promoting hand washing. For example, studies about knowledge of students regarding hand washing have shown that the majority of the students wash their after touching their genitals, before eating food and after visiting the toilets, but nothing has been talked about whether students wash their hands after coughing. Regarding this study, it was revealed that it is very important for students to always wash their hands after coughing because it helps in removing and killing germs that may be on their hands.

Studies on factors influencing hand washing among students have shown how the availability of water, tippy taps, and good hours of access influences one's behaviour to wash their hands but have ignored factors that contribute to poor adherence of hand hygiene like a failure by school head teachers and teachers to make hand hygiene an institutional priority. This gap was filled when a bigger number of students reported that they are more likely to wash their hands correctly when their teachers and prefects close to them, especially after using the toilets, before and after eating food. This means that for students to adhere to hand washing guidelines, there should be a combined effort between teachers and students.

\section{Methodology}

\section{Study Setting and Context}

The study was carried out in secondary schools of Ndorwa East Constituency in Kabale District, Southwestern Uganda. It is 409.24 KM from Kampala capital city of Uganda. Kabale district borders Rwanda from the South and East, Rukiga district from the North and Rubanda district from the West. Ndorwa East Constituency has 10 secondary schools, which include Kigata High school, Harambe High school, Kamuronko S.S, Kabanyonyi Vocational S.S, Nyakigugwe S.S, ST Robert Gay Nyanja S.S, Kyanamira S.S, Kahondo S.S, Buhara S.S, and Rwesasi S.S and the total number of students in these schools' totals to 2300 at this study time. The researcher chose this location because Kabale district is prone to outbreaks of diarrheal disease, especially Ndorwa west and Ndorwa east constituencies. In addition, Kabale is a border district with high potential of importing cases from neighbouring districts in Rwanda. This is attributed to the study by [16], who identified cholera hotspots along the borders of Uganda, although Kabale district was not included.

\section{Study Design}

The researcher employed a descriptive crosssectional survey research design that helped him in gathering information where little knowledge was known. A cross-sectional study using the quantitative method was conducted among 291 students from five schools. For qualitative data, the researcher used purposive sampling to identify the key informants and members to participate in FGDs. The researcher used a cross-sectional study design because it enables the researcher to study an independent variable and the dependent variable simultaneously, which also helped him to save time and costs during the study.

\section{Sample Size Determination and Sampling Procedure for Schools and Students}

\section{Schools}

The sample size for schools was determined using a maximum proportion of 0.5 recommended by [17]. When estimating the variance of a dichotomous variable (hand washing as yes/no), [17] recommends that researchers should use 0.50 as an estimate of the population proportion. This proportion will result in the maximization of variance, which will also produce the maximum sample size. In 
this study, therefore, 5 out of the 10 schools were used. The schools which were selected include Kigata High school, Harambe High school, Kamuronko S.S, Kabanyonyi Vocational S.S, and Nyakigugwe S.S.

\section{Students}

The researcher used [17] table to determine the sample size of the students to be used in the study. Since the total number of students in the five schools which were selected using multistage sampling was 1203 , the researcher had to subject the same number of students to Krejcie and Morgan's table and got the sample size as 291. Due to a non-response of $10 \%$ (participants did not show interest in answering the questions and those who were found absent), the sample size increased to 320 . The researcher opted to use this method because it is standard and easy to be used in selecting the required sample size. Simple random sampling was also used to identify the respondents to participate in the study from the selected schools.

Table 1. Sample Size Determination

\begin{tabular}{|l|l|l|l|l|l|}
\hline S/N & School Name & $\begin{array}{l}\text { Number of } \\
\text { Students }\end{array}$ & $\begin{array}{l}\text { No-Sampled } \\
\text { Per School }\end{array}$ & Non-Response & Actual Response \\
\hline 1 & Kigata High School & 490 & 130 & 11 & 119 \\
\hline 2 & $\begin{array}{l}\text { Kabanyonyi Vocational } \\
\text { Secondary school }\end{array}$ & 95 & 25 & 03 & 22 \\
\hline 3 & Kamuronko SS & 280 & 75 & 09 & 66 \\
\hline 4 & Harambe High School & 158 & 42 & 04 & 44 \\
\hline 5 & Nyakigugwe SS & 180 & 48 & 02 & 40 \\
\hline \multicolumn{2}{|l|}{ Total } & $\mathbf{1 2 0 3}$ & $\mathbf{3 2 0}$ & $\mathbf{2 9}$ & $\mathbf{2 9 1}$ \\
\hline
\end{tabular}

\section{Data Collection and Analysis}

Data collection was done using qualitative, quantitative, and observational methods.

Qualitative data were collected using Focus Group Discussions and Key Informant Interviews and observation, while Quantitative data were collected using semi-structured interviews.

Quantitative data were consolidated and edited, making sure that all questionnaires have proper identification numbers and that they are all complete. Data were entered and analyzed using a statistical computer package, called Statistical Package for Social Sciences (SPSS) version 20.0 and my analysis was restricted to uni-variate analysis. Descriptive statistics were used to analyze data regarding the demographic characteristics of respondents. The findings were presented in Table 2 as frequencies and percentages. Second, the practice of hand washing among Secondary School Students in
Ndorwa East Constituency Kabale District was presented using descriptive statistics, including frequencies and percentages.

The quality control measures that the researcher used include adequate numbering of the questionnaires, proper identification of the informants and field editing of the questionnaires. In addition, the researcher trained the research assistant who helped him to collect the intended data. During the data collection phase, the researcher, together with his research assistant, had to carry out supervision which helped him in getting the required data from the respondents.

\section{Ethical Considerations}

Since the study involved human beings as the respondents, the researcher had to ensure that their rights were highly protected. This included the right to privacy and dignity, the right to confidentiality, and the right to withhold participation. Participation was 
voluntary, and the principle of informed consent ensured this. For those who were considered to be minors, the researcher had to seek their consent from their parents and guardians through their head teachers.

The researcher had to first seek approval of the university research committee and research ethics committee and then after went to the District Education Officer of Kabale district to ask for permission to go and collect data from the secondary students in Ndorwa east constituency. Before collecting data in any of the selected schools, the researcher had to first seek permission from the head teachers as a way of avoiding interruptions and delays during the study. Lastly, the respondents' consent was obtained first after explaining the purpose of the study and that they were not to be forced to answer any questions found uncomfortable for them.

\section{Results}

A total of 291 respondents participated in the study. Study participants were both males and females of secondary school-aged below 12-22 years. A big number of participants were 12-17 years representing $80.1 \%$, and the class with the highest representation was senior two with $23 \%$ (67).

Table 2. Demographic Characteristics of the Respondents

\begin{tabular}{|l|l|l|l|}
\hline \multicolumn{2}{|l|}{ Parameter } & Frequency & Percentage \\
\hline Gender & Male & 105 & 36.1 \\
\cline { 2 - 4 } & Female & 186 & 63.9 \\
\cline { 2 - 4 } & Total & $\mathbf{2 9 1}$ & $\mathbf{1 0 0}$ \\
\hline \multirow{4}{*}{ Age range } & $12-17$ years & 233 & 80.1 \\
\cline { 2 - 4 } & $18-22$ & 58 & 19.9 \\
\cline { 2 - 4 } & Total & $\mathbf{2 9 1}$ & $\mathbf{1 0 0}$ \\
\hline Level of education & Senior 1 & 53 & 18.2 \\
\cline { 2 - 4 } & Senior 2 & 67 & 23.0 \\
\cline { 2 - 4 } & Senior 3 & 64 & 22.0 \\
\cline { 2 - 4 } & Senior 4 & 54 & 18.6 \\
\cline { 2 - 4 } & Senior 5 & 36 & 12.4 \\
\cline { 2 - 4 } & Senior 6 & 17 & 5.8 \\
\cline { 2 - 4 } & Total & $\mathbf{2 9 1}$ & $\mathbf{1 0 0}$ \\
\hline
\end{tabular}

Table 3. Practice of Hand Washing among Secondary School Students

\begin{tabular}{|l|l|l|l|}
\hline Practice of hand washing & Response & Frequency & Percentage \\
\hline \multirow{4}{*}{ Hand washing after the restroom } & Yes & 219 & 77.0 \\
\cline { 2 - 4 } & No & 72 & 23.0 \\
\cline { 2 - 4 } & Total & $\mathbf{2 9 1}$ & $\mathbf{1 0 0}$ \\
\hline \multirow{4}{*}{ Hand washing after coughing } & Yes & 122 & 42.0 \\
\cline { 2 - 4 } & No & 169 & 58.0 \\
\cline { 2 - 4 } & Total & $\mathbf{2 9 1}$ & $\mathbf{1 0 0}$ \\
\hline \multirow{3}{*}{$\begin{array}{l}\text { Hand washing with soap before } \\
\text { eating }\end{array}$} & Yes & 106 & 36.4 \\
\cline { 2 - 4 } & No & 185 & 63.6 \\
\cline { 2 - 4 } & Total & $\mathbf{2 9 1}$ & $\mathbf{1 0 0}$ \\
\hline
\end{tabular}

The findings in the above table indicated that the highest practice was washing hands after the students have been in their restrooms (77\%), followed by hand washing after coughing 122 (42\%), and hand washing before eating food which accounted for 106 (36.4\%). However, 
through observations made by the researcher, it was noted that 15 out $20(75 \%)$ students observed at school A washed their hands after using the toilet, 15 out of $22(68.2 \%)$ students washed their hands before eating food and 14 out of 16 students $(87.5 \%)$ washed their hands after eating food.

Table 4. Bivariate Analysis Results for Factors associated with Hand Washing among Secondary School Students

\begin{tabular}{|c|c|c|c|c|c|}
\hline \multirow{3}{*}{ Parameter } & & \multicolumn{2}{|c|}{ Hand washing practice } & \multirow[t]{3}{*}{ UOR $(95 \%$ CI $)$} & \multirow[t]{3}{*}{ p-value } \\
\hline & & \multirow{2}{*}{$\begin{array}{l}\text { Yes } \\
\mathrm{n}=279(95.9 \%)\end{array}$} & \multirow{2}{*}{$\begin{array}{l}\text { No } \\
\mathrm{n}=12(4.1 \%)\end{array}$} & & \\
\hline & & & & & \\
\hline \multicolumn{6}{|c|}{ Demographic factors } \\
\hline \multirow{2}{*}{ Gender } & Male & $103(36.9)$ & $2(16.7)$ & $2.9(0.63-13.62)$ & 0.1711 \\
\hline & Female & $176(63.1)$ & $10(83.3)$ & Reference & \\
\hline \multirow[t]{2}{*}{ Age range } & $12-17$ years & $229(82.1)$ & $4(33.3)$ & $9.2(2.65-31.61)$ & $0.001 *$ \\
\hline & $18-22$ & $50(17.9)$ & $8(66.7)$ & \multicolumn{2}{|l|}{ Reference } \\
\hline \multirow[t]{2}{*}{ Level of education } & Senior $1-4$ & $169(17.9)$ & $8(66.7)$ & & \\
\hline & Senior 5-6 & $49(23.7)$ & $4(33.3)$ & Reference & \\
\hline \multicolumn{6}{|l|}{ Facility factors } \\
\hline \multirow{2}{*}{$\begin{array}{l}\text { Presence of water } \\
\text { for hand washing }\end{array}$} & Yes & $256(91.8)$ & $2(16.7)$ & $55.7(11.50-269.38)$ & \multirow{2}{*}{$<0.001 *$} \\
\hline & No & $23(8.2)$ & $10(83.3)$ & Reference & \\
\hline \multirow{2}{*}{$\begin{array}{l}\text { Presence of hand } \\
\text { washing stations }\end{array}$} & Yes & $249(89.2)$ & $6(50.0)$ & $8.3(2.52-27.37)$ & \multirow{2}{*}{$<0.001 *$} \\
\hline & No & $30(10.8)$ & $6(50.0)$ & Reference & \\
\hline \multirow{2}{*}{$\begin{array}{l}\text { Provision of soap } \\
\text { for hand washing }\end{array}$} & Yes & $90(32.3)$ & $6(50.0)$ & $0.5(0.15-1.52)$ & \multirow{2}{*}{0.2096} \\
\hline & No & $189(67.7)$ & $6(50.0)$ & Reference & \\
\hline \multirow{3}{*}{$\begin{array}{l}\text { Cleanliness of } \\
\text { stations }\end{array}$} & Yes & $220(87.3)$ & $1(8.7)$ & $75.6(9.44-605.6)$ & \multirow{3}{*}{$0.001 *$} \\
\hline & No & $32(12.7)$ & $11(91.7)$ & Reference & \\
\hline & No & $151(53.9)$ & $8(66.7)$ & Reference & \\
\hline
\end{tabular}

*Significance level, $\mathrm{p}<0.05$

In the absence of other factors (Bivariate analysis), being aged 12-17 years (UOR $=9.2$, 95\%CI: (2.65-31.61): $p=0.001)$, presence of water for hand washing (UOR: 55.7, 95\%CI: $11.50-269.38, \quad p<0.001)$, presence of hand washing stations (UOR: 8.3, 95\%CI: 2.5227.37, $p<0.001)$, and clean hand washing facilities (UOR: 75.6, 95\%CI: 9.44-605.6, $p=$ $0.001)$ were the factors associated with good hand washing practices at $95 \%$ level of significance. Other factors which were associated with hand washing practices were the functionality of hand washing stations, being comfortable with the hours of accessing hand washing stations and supervising students during hand washing by teachers and student leaders.
Data collected using the checklist by the researcher revealed that at least three out of five schools $(60 \%)$ that were studied had tippy taps installed to support hand washing among students, and the rest had cemented taps, $60 \%$ had water in taps for washing hands, $60 \%$ of the schools visited did not have soap for students to use while washing hands and $100 \%$ of the schools had a reliable water source for washing hands (both tippy taps and cemented taps) in the school compounds.

\section{Discussion}

This study examined the hand washing practices among secondary school students in Ndorwa Constituency in Kabale District. The study findings have revealed almost all the 
secondary school students were involved in the hand washing practice; most hand washing practice took place after they have been in the rest rooms. This indicates that the participants are aware that washing hands helps in removing contaminants they might have come into contact with while in the restrooms, which should also be encouraged among students if they are to keep their hands clean all the times. This relates to what the health belief model, which supported my study, says that a person will follow a preventive behaviour such as hand washing if he or she perceives that there are benefits associated with it. The findings are in line with those of [9] who found out that over $90 \%$ of school children in China who visited the restroom washed hands with soap and water.

It was also revealed that a majority of the students could not wash their hands with soap before eating food which is an indicator that they do not know the importance of soap in removing and killing disease contaminants that may be on their hands. This finding also do not relate to what the Health Belief Model talks about that a person will follow a preventive behaviour if he or she perceives that they are susceptible to a risk of contracting diseases associated with poor hand washing practices such as diarrhoea, cholera and dysentery. These results are in agreement with a survey that was undertaken by [9], which showed that the majority of the students in China did not exercise proper hand washing using soap as a result of lack of access to hand washing supplies such as soap, towel, and a clean running source of water. The results of this study also agree with [18], who reported that being in a dining hall does not guarantee students to wash their hands with soap. This implies that there is a need to sensitize secondary school students on the appropriate times of the hand washing practices. This finding has important policy implications for health intervention and supports the view that the provision of hand washing soap to all schools would help students to avoid diseases that may be associated with dirty hands.

In this study, it was indicated that a big number of participants could not wash their hands after coughing. This practice is dangerous because it increases the chances of spreading diseases such as tuberculosis and the common cold amongst the student population through hand shaking with others in case the diseased person does not wash hands after coughing. The findings are not in line with [19], who noted that keeping hands clean through improved hand hygiene is one of the most important ways to prevent sickness and to spread of germs to others, good hand washing can also fight the spread of the common cold, meningitis, bronchitis, Tuberculosis, influenza, hepatitis A, and most types of infectious diarrhoea. Therefore, the finding has important policy implications for health intervention and sensitizing the students to always wash hands even after coughing because it is helpful in removing the germs that may be associated with the cough.

In this study in which the factors associated with hand washing were assessed, it was found out that presence of water for hand washing, presence of hand washing stations in schools, the functionality of hand washing facilities by students to clean their hands and the presence of hand washing stations that were clean were the factors associated with hand washing by students while at school. Besides, the majority of the respondents indicated that secondary school students have access to water for hand washing in their schools. This could be due to factors like access to funds from both the government and directors of private schools, which would facilitate the construction of hand stations and filling them with enough water in schools where students indicated that they do not have access to water for hand washing. The field findings disagree with a similar study which was conducted by [20] which revealed that out of 200 Columbian school children, only $7 \%$ of the children reported having clean water 
for hand washing. Other studies by [21] reported similar findings.

The majority of the secondary school students had hand washing stations in their schools. The majority of the students indicated that they had hand washing stations installed in their schools, but it could be better if such hand washing stations can also be extended to schools which do not have them by the government and owners of private ones. In a related study by [22] about hand washing practices among elementary school students in the Selat sub-district in Indonesia, two thirds $(65.9 \%)$ of the respondents reported the availability of clean water at washing stands, $68.5 \%$ stated that soap was available at the stands, and $73.7 \%$ declared that hand washing stands were available at schools.

Further, in this study, it was indicated that most secondary schools could not provide them with soap for hand washing. This practice is not good and should be discouraged in all the schools because washing hands without soap cannot remove or kill germs which may be on hands, and as a result, students end up suffering from diseases associated with poor hand washing practices. The findings are not in line with the study by [22], where $68.5 \%$ of his study participants stated that soap was available at the stands, which would encourage most of them to properly practice hand washing. These findings also disagree with [23], who revealed that for students to wash their hands properly, they must be provided with detergents like soap if they are to prevent themselves from infections/ illnesses related to poor hand hygiene. This finding also has important policy implications because health policy stipulates that it is very important to wash hands with the help of soap as it helps to kill germs which may be dangerous to people. WHO organization states that washing hands with soap at critical times such as before meals and after toilet use have been found to prevent hepatitis A infection, thus it is appropriate for disease control and prevention programs to as focus on hand washing as well as preventive intervention.

In addition, the findings from this study indicated that most hand washing stations in schools were clean. This is an important practice which should be maintained because it reduces the risk of contracting diseases which are associated with poor hygiene practices diarrhoea, typhoid, among others. Such findings are in line with the results of the study done by [24], who revealed that clean hand washing facilities motivate people to wash their hands, which minimizes the risk of infection.

\section{Conclusion}

From the findings, it can be concluded that the majority of secondary school students washed their after they have been in the restroom, after using the toilet, before after eating food and after coughing; most hand washing practice took place after they had been in the restrooms. Although the majority of the students washed their hands, most of them could not wash their hands with soap, especially before eating food.

\section{Recommendations}

The study suggests that the school administrators and teachers should continue sensitizing all students on assemblies and in school health clubs to continue practicing washing hands, especially after using the toilets, before and after eating food and after coughing. This would help in preventing students from diseases associated with poor hand hygiene practices.

The study suggests the school administrators, together with the teachers in Ndorwa East Constituency, should allocate enough funds for putting up better hand washing facilities like tippy taps and soap to support hand washing among students.

\section{Acknowledgement}

School administration and students for the cooperation exhibited during data collection. 


\section{Funding}

The study was privately funded.

\section{References}

[1] UNICEF, 2016. One is too many: Ending child deaths from pneumonia and diarrhea.

[2] Curtis, V. and Cairncross, S. (2012). Effects of washing hands with soap on diarrhea risk in the country: a systematic review. Published by Lancet Publishing Group, London.

[3] Center for Disease Control and Prevention. 2020. Wash your hands. Atlanta. From: http://www.cdc.gov/features/handwashing/ (accessed 17 July 2020).

[4] World Health Organization. (2010). WHO Guidelines on Hand Hygiene in Health Care First Global.

[5] World Health Organization. (2013). Importance of good hand hygiene for patient safety.

[6] Global Handwashing Partnership. (2017). The State of Handwashing in 2016: Annual Review, (March), 1-11.

[7] UNICEF, (2014) Report of the African Conference on the empowerment of the girl child. Kampala: UNICEF Esaro.

[8] Arthi, E., Abarna, V., Bagyalakshmi, R., Anitharaj, M., \& Vijayasree, S. (2016). Assessment of Knowledge, Attitude and Practice of Hand Hygiene among Nursing and Medical Students in a Tertiary Care Hospital in, 3(4), 1203-1206.

[9] Asiedu M. S., Vaness S. E., Papoe M., Setorglo J., Asiedu D. K., and Anderson A. K. (2011). Hand washing practices among school children in Ghana.

[10]Ejemot-N et al. (2015) Hand washing promotion for preventing diarrhoea. Cochrane Database of Systematci Reviws 44-43.

[11] United Nations Children's Fund, (2013). Soap, Toilets, and Taps. A foundation for Health Children.

Available at:

https://www.globalhandwashingday.org/.

[12] Government of Uganda Ministry of Water and Environment Water and Environment Sector Performance Report 2019.

\section{Conflict of Interest}

No conflict of interest declared.

[13] World Health Organization, (2015): Prevention of blindness. International ear Care Day 2015: Making listening safe. http://WHO.com Accessed April 2015.

[14] The Uganda Human Rights Commission (2012). 11th Annual Report of the Uganda Human Rights Commission to the Parliament of the Republic of Uganda.

[15]Bwire et al. (2017) Identifying Cholera "hotspots" in Uganda. An analysis of Cholera surveillance data from 2011 to 2016.

[16] Miller, M. J. 2012. Reliability and validity. Available:

http://michaeljmillerphd.com/res500_lecturenotes/R eliability_and_Validity.pdf Accessed:3 March 2019. [17] Borchgrevink, C. P., Cha, J., \& Kim, S. (2013). Hand washing practices in a college town environment. Journal of Environmental Health, 75(8), 18-24. Retrieved from http://www.ncbi.nlm.nih.gov/pubmed/23621052.

[18] UNICEF (2005).Child-friendly hygiene and sanitation facilities in schools. Publication@ irc.nl.

[19]Mbula, E. S. (2013). Factors influencing implementation of hygiene practices in public secondary schools in the central division of Machakos district in Machakos county by.Nabavi, M., Alavi-Moghaddam, Nadakavukaren, A. (2011). Food quality. Our global environment: A health perspective. Waveland Press, Incorporated.

[20] Taylor, J. K, Basco, R, Zaied, A, \& Ward, C. (2010). Hand hygiene knowledge of college students. The importance of handwashing. (2017), (July).

[21]Mbula, E. S. (2013). Factors influencing implementation of hygiene practices in public secondary schools in central division of machakos district in machakos county by.Nabavi, M., AlaviMoghaddam, Nadakavukaren, A. (2011). Food quality. Our global environment: A health perspective. Waveland Press, Incorporated.

[22] Setyautami, T., Sermsri, S., \& Chompikul, J. (2012). Proper hand washing practices among 
elementary school students in Selat sub-district, Indonesia, 10(2). Setyautami, T, Sermsri, S, \& Chompikul, J. 2011. Proper hand washing practices among elementary school students in Selat subdistrict, Indonesia.

[23] Taylor, J. K, Basco, R, Zaied, A, \& Ward, C. (2010). Hand hygiene knowledge of college students. The importance of handwashing. (2017), (July).
[24]Dhiraj et al 2015. Quantification of perception status of hand washing practice among schoolchildren in a rural area of west bengal. 